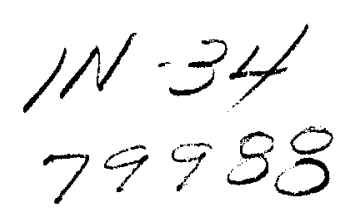

NASA Contractor Report 189133

P.10

\title{
Interfacial Tension Measurement of Immiscible Liquids Using a Capillary Tube
}

\author{
N. Rashidnia \\ Sverdrup Technology, Inc. \\ Brook Park, Ohio \\ R. Balasubramaniam \\ Case Western Reserve University \\ Cleveland, Ohio
}

and

D. Del Signore

University of Toledo

Toledo, Ohio

March 1992

Prepared for

Lewis Research Center

Under Contract NAS3-25266

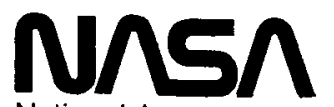

National Aeronautics and

Space Administration

$$
\begin{aligned}
& \text { (NACA-CW-13713) INTFRFACIAL TENSIOW } \\
& \text { MEACUCEMENT GF INATCIBLE LIU UIUS USTAO A } \\
& \text { CAPILLAPY TUE (svartrup Technology) } 10 \mathrm{p} \\
& \text { CSCL } 200 \text { unclas } \\
& 192-21262 \\
& 63 / 340079338
\end{aligned}
$$




\title{
INTERFACIAL TENSION MEASUREMENT OF IMMISCIBLE LIQUIDS
}

\section{USING A CAPILLARY TUBE}

\author{
N. Rashidnia \\ R. Balasubramaniam* \\ Sverdrup Technology, Inc. \\ Case Western Reserve University \\ Cleveland, Ohio 44106 \\ D. Del Signore \\ Lewis Research Center Group \\ Brook Park, Ohio 44142 \\ University of Toledo \\ Toledo, Ohio 43606
}

\section{Introduction:}

The interfacial tension of immiscible liquids is an important thermophysical property that is useful in the behavior of liquids both in microgravity (Martinez et al (1987), Karri and Mathur (1988)) and in enhanced oil recovery processes under normal gravity (Slattery (1974)). Many techniques are available for its measurement, such as the ring method, drop weight method, spinning drop method, and capillary height method (Adamson (1960), Miller and Neogi (1985)). Karri and Mathur mention that many of the techniques use equations that contain a density difference term and are inappropriate for equal density liquids. They reported a new method that is suitable for both equal and unequal density liquids. In their method, a capillary tube forms one of the legs of a U-tube. The interfacial tension is related to the heights of the liquids in the cups of the U-tube above the interface in the capillary. Our interest in this area arose from a need to measure small interfacial tensions (around $1 \mathrm{mN} / \mathrm{m}$ ) for a vegetable oil / silicone oil system that was used in a thermocapillary drop migration experiment (Rashidnia and Balasubramaniam (1991)). In our attempts to duplicate the method proposed by Karri and Mathur, we found it quite difficult to anchor the interface inside the capillary tube; small differences of the liquid heights in the cups drove the interface out of the capillary.

We present an alternative method using a capillary tube to measure the interfacial tensions of

*NASA Resident Research Associate at Lewis Research Center. 
liquids of equal or unequal density. The method is based on the combined capillary rises of both liquids in the tube, with air being the medium above the liquids. This way of using the capillary tube is different from those used previously, such as by Clarkson (1984). Also, in this method, no difficulties are encountered in anchoring the interface inside the capillary tube as in our attempts to duplicate the method by Karri and Mathur.

\section{Principle:}

A simple sketch of the combined capillary rise method is shown in Figure 1a. A large container contains the two immiscible liquids, one on top of the other. A capillary tube is dipped into the upper liquid (liquid 1) to measure its surface tension with air $\left(\sigma_{1 \mathrm{a}}\right)$. Then, the capillary tube is pushed further down into the lower liquid (liquid 2) so that a liquid-liquid interface is present in it. This is best accomplished by using a pinch cork attached to a flexible tube connected to the top of the capillary before pushing it down into liquid 2. Upon releasing the pinch cork, the liquid-liquid interface naturally rises into the capillary (for wetting liquids).One may also establish $1 \mathrm{a}$ and 12 interfaces inside the capillary tube without having the two liquids in contact in the outer container. This is accomplished by dipping the capillary tube first into liquid 1 , and subsequently, without allowing the column of liquid 1 to drain, dipping it into a container of liquid 2. This is in fact the preferred approach especially for equal density liquids and is used in the experiments reported here. For this case, the height $\mathrm{L}_{1}$ (Figure 1a) is zero. Assuming the interface 12 and la to be spherical, the following equation may easily be derived for the interfacial tension

$$
\sigma_{12}=-\sigma_{1 \mathrm{a}} \frac{\cos \theta_{1 \mathrm{a}}}{\cos \theta_{12}}+\frac{\mathrm{gr}}{2 \cos \theta_{12}}\left(\rho_{1} \mathrm{~h}_{1}+\rho_{2} \mathrm{~h}_{2}-\rho_{1} \mathrm{~L}_{1}\right)
$$

where $\sigma$ is interfacial tension, $\theta$ is contact angle, $g$ is earth's gravitational acceleration, $r$ is the capillary tube radius and $\rho$ is liquid density. The various liquid heights are defined in Figure 1a. In deriving the above equation, the curvatures of both interfaces in the container are assumed to be zero. While this is easily realized for unequal density liquids, it is not necessarily the case for equal density liquids. For the data reported here, $L_{1}$ is zero and so this situation does not arise. Specializing eq(1) for equal density liquids, the following equation 
may be obtained

$$
\sigma_{12}=-\sigma_{1 a} \frac{\cos \theta_{1 a}}{\cos \theta_{12}}+\frac{\rho g r}{2 \cos \theta_{12}}\left(h_{1}+h_{2}-L_{1}\right)
$$

Equations 1 and 2 involve both the contact angles $\theta_{1 \mathrm{a}}$ and $\theta_{12}$. If the capillary tube is itself used to measure $\sigma_{1 \mathrm{a}}, \theta_{1 \mathrm{a}}$ drops out of eq(1) because the capillary rise measured is

$$
\mathrm{h}=\left(2 \sigma_{1 \mathrm{a}} \cos \theta_{1 \mathrm{a}}\right) /\left(\rho_{1} \mathrm{gr}\right)
$$

which may be used directly in eq(1). $\theta_{12}$ may be obtained from the geometry of the interface within the capillary (Figure 1b). Assuming a spherical interface

$$
\theta_{12}=\cos ^{-1}\left(2 \mathrm{k} /\left(\mathrm{k}^{2}+1\right)\right)
$$

where $\mathrm{k}=\mathrm{y} / \mathrm{r}$. If $\theta_{12}$ is less than ten degrees, the error in assuming it to be zero in eq(1) or eq(2) is less than $1.5 \%$. The working equation used to calculate $\sigma_{12}$ for the case with $L_{1}=0$ is

$$
\sigma_{12}=\operatorname{gr}\left[\rho_{1}\left(\mathrm{~h}_{1}-\mathrm{h}\right)+\rho_{2} \mathrm{~h}_{2}\right] /\left(2 \cos \theta_{12}\right)
$$

\section{Experimental Procedure:}

Pyrex glass capillary tubes with an ID of $1.15 \mathrm{~mm}$ and length of $10 \mathrm{~cm}$ are used. The liquids are contained in quartz cells of inner dimensions $1 \times 1 \times 4.5 \mathrm{~cm}$ and a thickness of $1.25 \mathrm{~mm}$. All the measurements reported are at room temperature (around $21 \mathrm{deg} C \pm 2 \mathrm{deg} C$; the room temperature was steady during the course of every experiment to $\pm 0.5 \mathrm{deg} C$ ). The top end of the capillary is connected via a rubber tubing to a suction device. The apparatus is mounted on an optical table; no vibration isolation is provided.

Before each experiment, the capillary tubes and the quartz cells are cleaned as follows. They are immersed in a micro cleaning solution mixed with water and allowed to stand overnight. They are then cleaned and rinsed with distilled water. This is followed by rinsing with acetone, methanol and distilled water, in that order. Finally they are dried in a vacuum oven at $120 \mathrm{deg} \mathrm{C}$ for an hour.

The capillary tube is first dipped into liquid 1 and then into liquid 2 to establish liquidl/air and liquid1/liquid2 interfaces within it. To ensure that the interfaces are in equilibrium locations 
and the capillary tube is wetted by the liquids, a small suction followed by a release to atmospheric pressure is applied a few times to the top of the capillary. The equilibrium locations are stable and repeatable. The interfaces are established quite rapidly (a few minutes maximum) using the present method. The various heights needed for the measurement of $\sigma_{1 \mathrm{a}}$ and $\sigma_{12}$ are obtained using a cathetometer. Typical heights are on the order of 3 to $15 \mathrm{~mm}$ and the cathetometer resolution is $0.01 \mathrm{~mm}$. A stereo microscope is used to measure the diameter of the capillary tube (diameter is $1.15 \pm 0.015 \mathrm{~mm}$ ) and the lengths required to calculate $\theta_{12}$

Distilled water is used as liquid 2 in all the cases except for the anisaldehyde / ethylene glycol pair, for which liquid 2 is ethylene glycol. For many cases, there is density inversion within the capillary; however, no instability is observed and the $1 \mathrm{a}$ and 12 interfaces are stable in all the experiments reported.

\section{Results and Discussion:}

Interfacial tensions of nine liquid pairs (Table 1) have been measured using the combined capillary rise method proposed here (with $\mathrm{L}_{1}=0$ ). They cover a fairly wide range of values of the interfacial tension and the density difference between the liquids. Figure $2 \mathrm{a}$ and $2 \mathrm{~b}$ show the interfaces obtained in the quartz cell and in the capillary tube for cyclohexane/water and benzaldehyde/water systems respectively (in these pictures $L_{1} \neq 0$ ). Representative measurements of the contact angle $\left(\theta_{12}\right)$ for all the systems in Table 1 revealed that $\theta_{12}$ is less than ten degrees; hence $\theta_{12}$ has been assumed to be zero in $\mathrm{Eq}(5)$ for computing the interfacial tensions.

Table 1 presents the results for the interfacial tensions. The sample standard deviations are less than $0.5 \mathrm{mN} / \mathrm{m}$ (typically around $2 \%$ of the mean); thus the data is very reproducible. The accuracy of the cathetometer used is $0.01 \mathrm{~mm}$. However, the interfaces appear thicker in the cathetometer field of view due to refraction effects; hence placement of the cross-hairs has an 
inherent error. If we assume a worst case error of $0.1 \mathrm{~mm}$ in measuring liquid heights in the capillary (typical heights are 3 to $15 \mathrm{~mm}$ ), this would indicate a $2-3 \%$ cumulative error in the interfacial tension. Comparing the measured interfacial tensions with those in the literature, it is seen that for non-equal density liquids the agreement is good, with a maximum deviation of 9.3\% for octanol/water and benzaldehyde/water interfaces. The experiments did indicate that benzaldehyde was very prone to coat the glassware with crystals; it is not clear whether this plays a role. The interfacial tensions for cyclohexane, carbontetrachloride and octanol with water are slightly lower than those in the literature (Donahue and Bartell (1952) and Girifalco and Good (1957)). For equal density liquids the agreement of our data with the results of Karri and Mathur is much worse. The maximum deviation is $32 \%$ for benzonitrile/water interface. Karri and Mathur report the interfacial tension of 3-phenyl-1-propanol with water to be zero, while the measurements herein indicate the value to be around $7.9 \mathrm{mN} / \mathrm{m}$. We found that the cleanliness of the tubes and experiment cells are crucial in order to measure the interfacial tensions with repeatability; hence we strictly followed the cleaning procedure mentioned earlier The liquids used are of ordinary purity and not high purity. Other than general laboratory precautions, no additional steps have been taken to ensure the purity of the liquids and the interfaces. Thus, as in all surface tension measurements, cleanliness remains an issue. This perhaps plays a role in the deviations between the current measurements and the literature values. In view of the large deviations, independent measurements are needed to confirm the accuracy of the interfacial tensions of the equal density liquids in Table 1.

While the lowest interfacial tension measured with the combined capillary rise technique is reported to be around $3.4 \mathrm{mN} / \mathrm{m}$ in Table 1 , lower values around $1 \mathrm{mN} / \mathrm{m}$ have also been measured for the neutral density liquid pair comprising of silicone oil and vegetable oil, in order to measure d $\sigma / \mathrm{dT}$ in the temperature range 20 to $50 \mathrm{deg} \mathrm{C}$, (Rashidnia and Balasubramaniam). Thus it appears that the combined capillary rise technique can be used for a broad range of interfacial tensions. Additional testing is required to establish the accuracy of the method for a larger class of immiscible liquid pairs especially of equal density. 


\section{References:}

A. W. Adamson (1960),"Physical Chemistry of Surfaces," Interscience Publishers Inc.

M. T. Clarkson (1984),"Measurements on the Liquid Rise in Glass Capillaries at Micro emulsion/Oil/Brine Interfaces," Journal of Colloid and Interface Science, Vol 102, No 2, pp 563-566.

D. J. Donahue and F. E. Bartell (1952),"The Boundary Tension at Water-Organic Liquid Interfaces," J. Phys. Chem., 56, 480.

L. A. Girifalco and R. J. Good(1957),"A Theory for the Estimation of Surface and Interfacial Energies I. Derivation and Application to Interfacial Tension,"J. Phys. Chem., 61, 904.

S. B. Reddy Karri and V. K. Mathur (1988),"Measurement of Interfacial Tension of Immiscible Liquids of Equal Density,"AIChE J., Vol 34, N0 1, pp 155-157.

I. Martinez, J. M. Haynes and D. Langbein(1987),"Fluid Statics and Capillarity," in Fluid Sciences and Material Sciences in Space, H. U. Walter (ed), pp 53-81, Springer-Verlag, Berlin.

C. A. Miller and P. Neogi (1985),"Interfacial Phenomena," Marcel Dekker Inc., New York.

N. Rashidnia and R. Balasubramaniam (1991),"Thermocapillary Migration of Liquid Droplets in a Temperature Gradient in a Density Matched System," Experiments in Fluids, Vol 11, pp 167-174.

J. C. Slattery,"Interfacial Effects in the Entrapment and Displacement of Residual Oil," AIChE J., Vol 20 No 6, pp 1145-1154. 
Table 1.

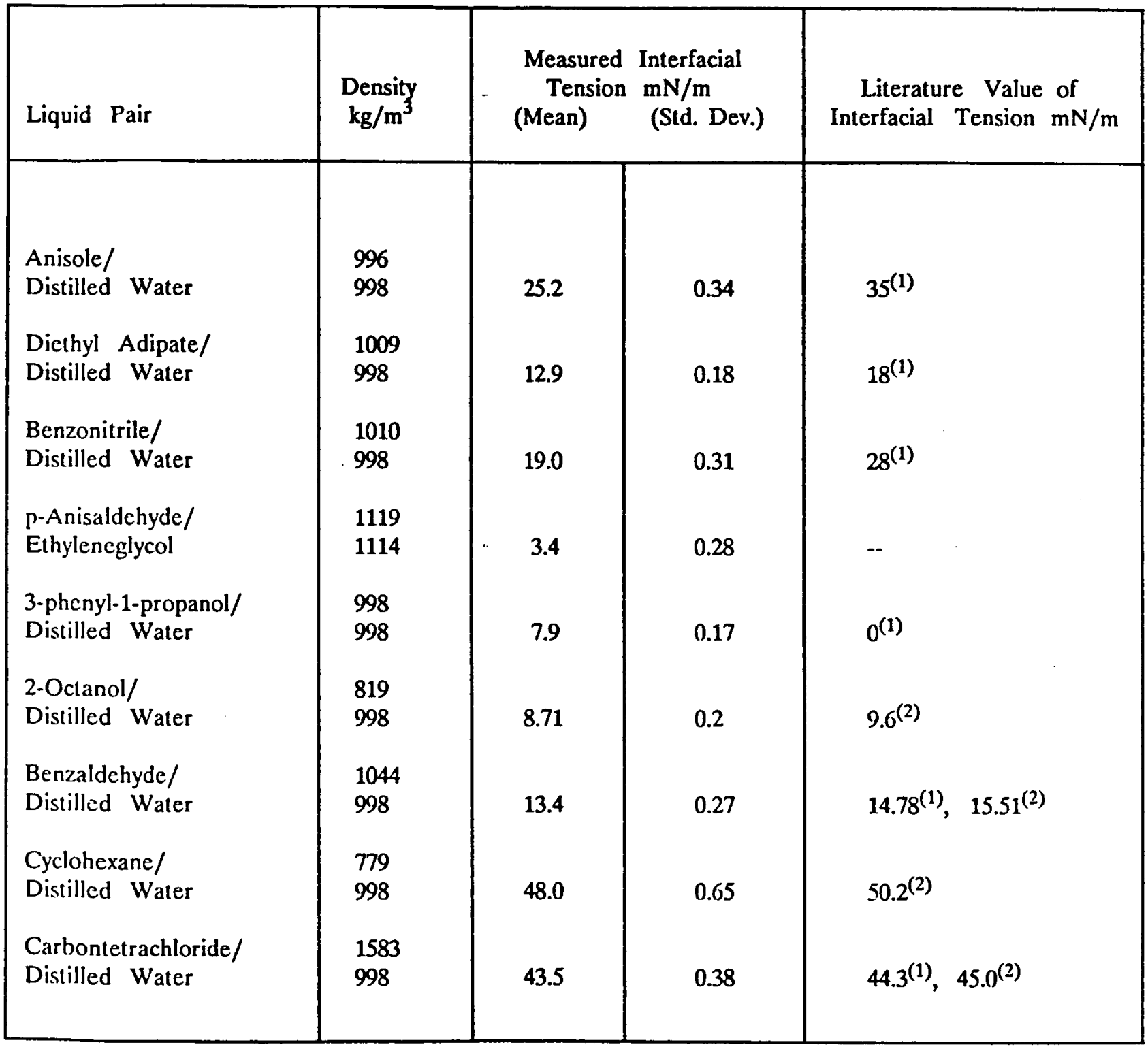

(1) Karri and Mathur (1988)

(2) Girifalco and Good (1957) 

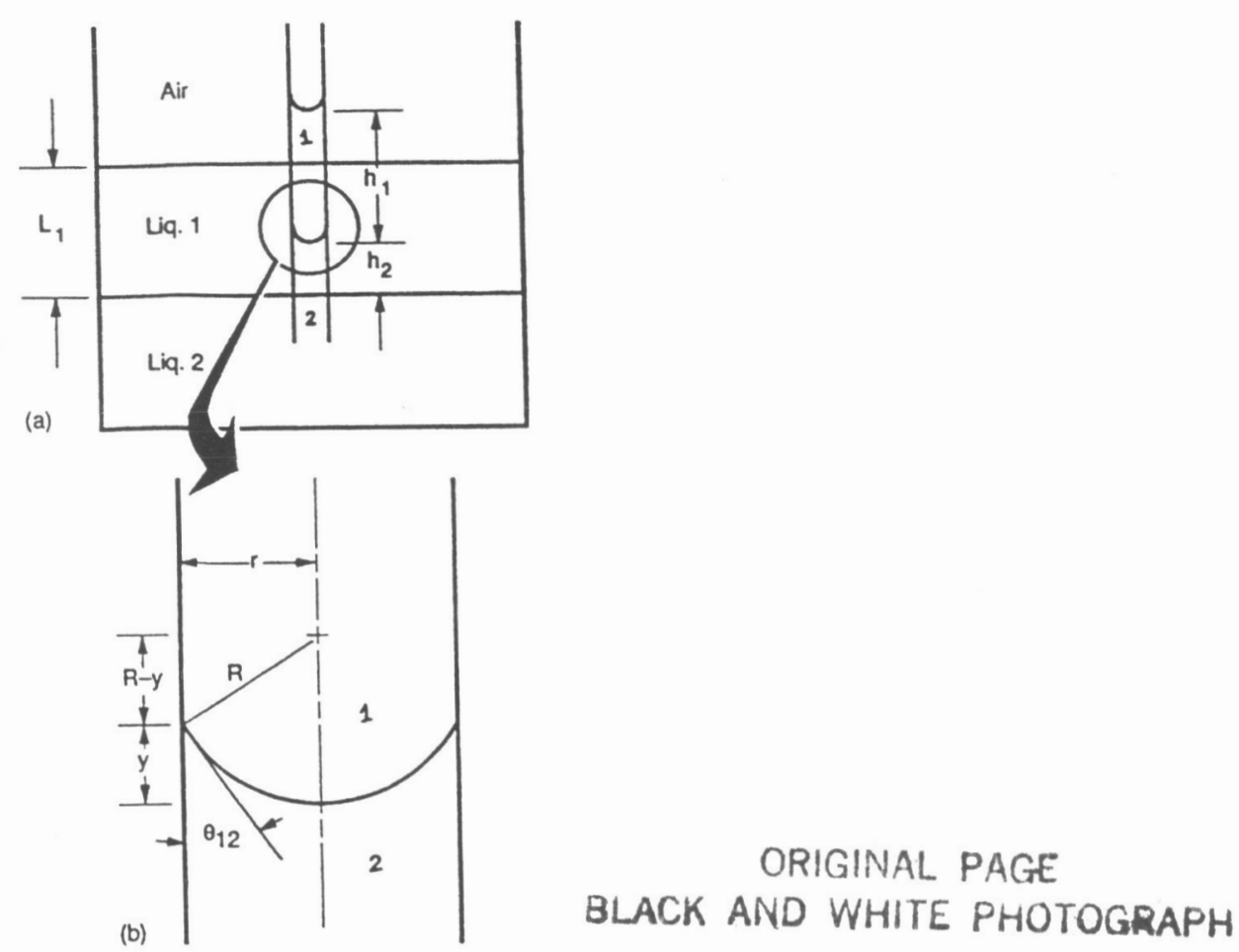

Figure 1. -Principle of the combined capillary rise method.

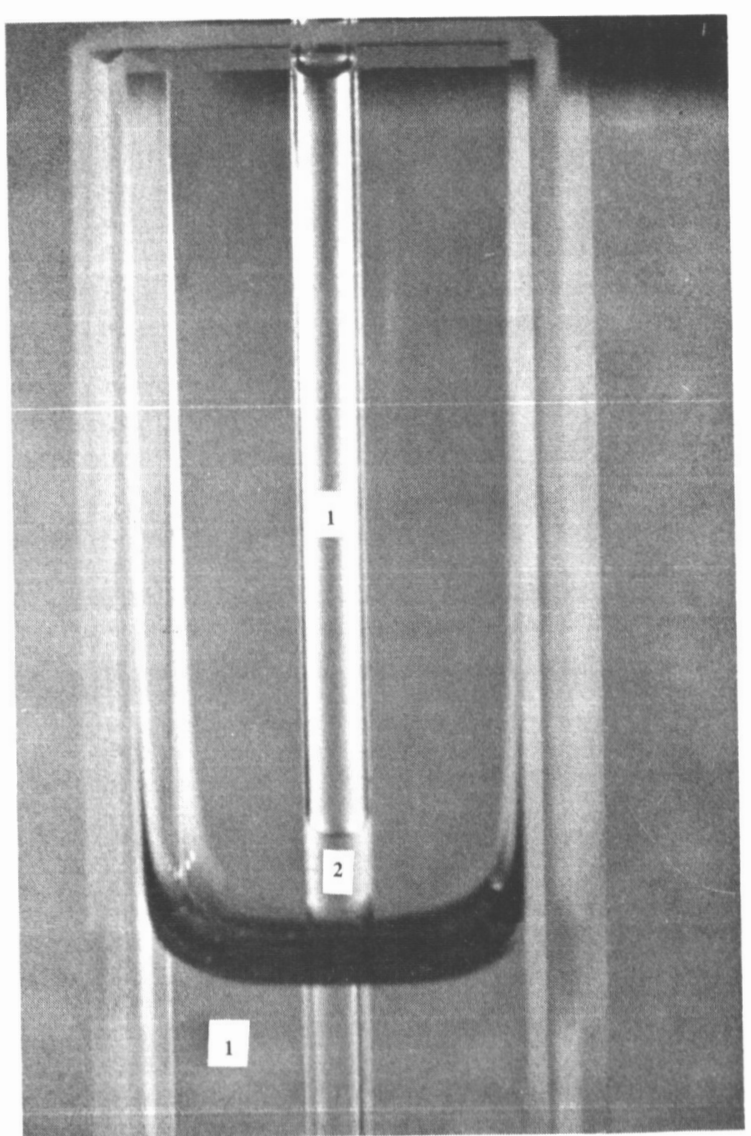

(a) Cyclohexane/water system.

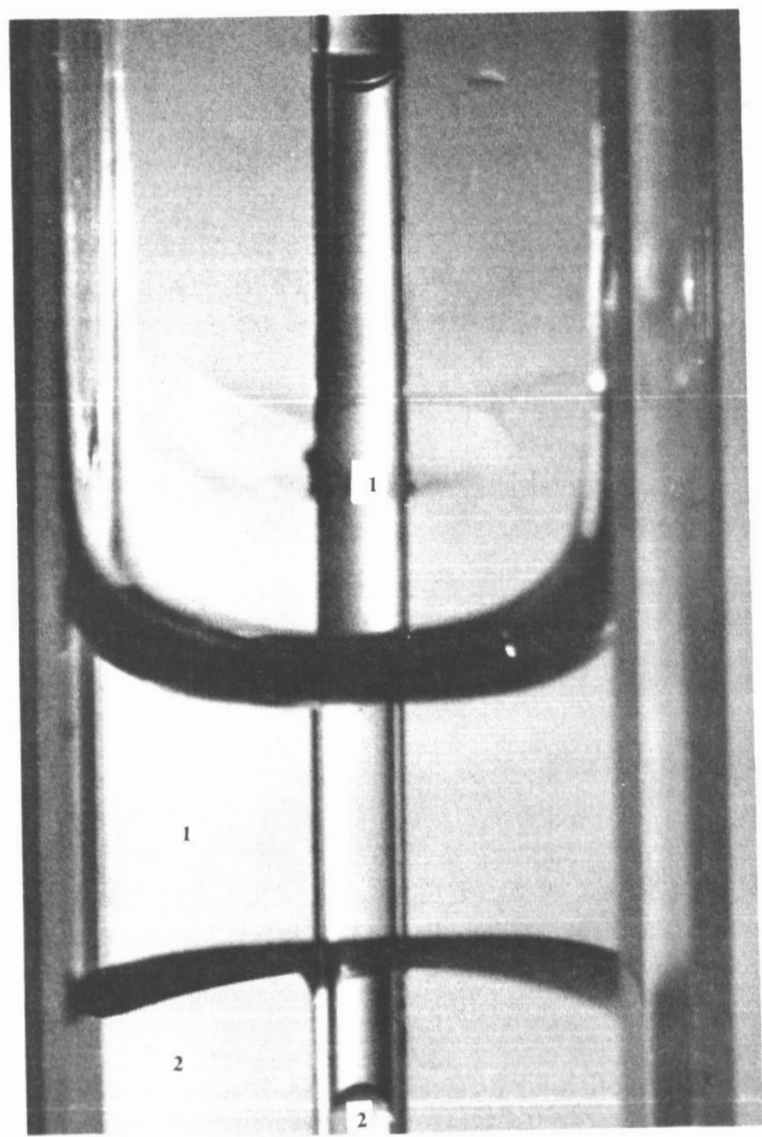

(b) Benzaldehyde/water system.

Figure 2. -The combined capillary rise method. 


\begin{tabular}{|c|c|c|c|}
\hline \multicolumn{3}{|c|}{ REPORT DOCUMENTATION PAGE } & $\begin{array}{l}\text { Form Approved } \\
\text { OMB No. } 0704-0188\end{array}$ \\
\hline \multicolumn{4}{|c|}{$\begin{array}{l}\text { Public reporting burden for this collection of information is estimated to average } 1 \text { hour per response, including the time for reviewing instructions, searching existing data sources } \\
\text { gathering and maintaining the data needed, and completing and reviewing the collection of information. Send comments regarding this burden estimate or any other aspect of thi } \\
\text { collection of information, including suggestions for reducing this burden, to Washington Headquarters Services, Directorate for intormation Operations and Reports, } 1215 \text { Jefferson } \\
\text { Davis Highway, Suite 1204, Arlington, VA 22202-4302, and to the Office of Management and Budget, Paperwork Reduction Project (0704-0188), Washington, DC 20503. }\end{array}$} \\
\hline 1. AGENCY USE ONLY (Leave blank) & $\begin{array}{l}\text { 2. REPORT DATE } \\
\text { March } 1992\end{array}$ & 3. & $\begin{array}{l}\text { DDATES COVERED } \\
\text { inal Contractor Report }\end{array}$ \\
\hline \multicolumn{3}{|c|}{$\begin{array}{l}\text { 4. TITLE AND SUBTITLE } \\
\text { Interfacial Tension Measurement of Immiscible Liquids Using a } \\
\text { Capillary Tube }\end{array}$} & 5. FUNDING NUMBERS \\
\hline \multicolumn{3}{|c|}{$\begin{array}{l}\text { 6. AUTHOR(S) } \\
\text { N. Rashidnia, R. Balasubramaniam, and D. Del Signore }\end{array}$} & C-NAS3-25266 \\
\hline \multicolumn{2}{|l|}{$\begin{array}{l}\text { Sverdrup Technology } \\
\text { Lewis Research Center Group } \\
\text { Brook Park, Ohio } 44142\end{array}$} & & $\begin{array}{l}\text { 8. PERFORMING ORGANIZATION } \\
\text { REPORT NUMBER }\end{array}$ \\
\hline \multicolumn{3}{|c|}{$\begin{array}{l}\text { National Aeronautics and Space Administration } \\
\text { Lewis Research Center } \\
\text { Cleveland, Ohio } 44135-3191\end{array}$} & $\begin{array}{l}\text { 10. SPONSORING/MONITORING } \\
\text { AGENCY REPORT NUMBER } \\
\text { NASA CR-189133 }\end{array}$ \\
\hline \multicolumn{4}{|c|}{$\begin{array}{l}\text { 11. SUPPLEMENTARY NOTES } \\
\text { Project Manager, Richard Vernon, Space Experiments Division, NASA Lewis Research Center, (216) } 433-2875 \text {. N. Rashidnia, Sverdrup } \\
\text { Technology Inc.; R. Balasubramaniam, Case Western Reserve University, Cleveland, Ohio } 44106 \text { and NASA Resident Research Associate } \\
\text { at Lewis Research Center; D. Del Signore, Department of Mechanical Engineering, University of Toledo, Toledo, Ohio } 43606 .\end{array}$} \\
\hline \multicolumn{3}{|c|}{ 12a. DISTRIBUTION/AVAILABILITY STATEMENT } & 12b. DISTRIBUTION CODE \\
\hline
\end{tabular}

\section{ABSTRACT (Maximum 200 words)}

The interfacial tension of immiscible liquids is an important thermophysical property that is useful in the behavior of liquids both in microgravity (Martinez et al. (1987), Karri and Mathur (1988)) and in enhanced oil recovery processes under normal gravity (Slattery (1974)). Many techniques are available for its measurement, such as the ring method, drop weight method, spinning drop method, and capillary height method (Adamson (1960), Miller and Neogi (1985)). Karri and Mathur mention that many of the techniques use equations that contain a density difference term and are inappropriate for equal density liquids. They reported a new method that is suitable for both equal and unequal density liquids. In their method, a capillary tube forms one of the legs of a U-tube. The interfacial tension is related to the heights of the liquids in the cups of the U-tube above the interface in the capillary. Our interest in this area arose from a need to measure small interfacial tensions (around $1 \mathrm{mN} / \mathrm{m}$ ) for a vegetable oil/ silicone oil system that was used in a thermocapillary drop migration experiment (Rashidnia and Balasubramaniam (1991)). In our attempts to duplicate the method proposed by Karri and Mathur, we found it quite difficult to anchor the interface inside the capillary tube; small differences of the liquid heights in the cups drove the interface out of the capillary. We present an alternative method using a capillary tube to measure the interfacial tensions of liquids of equal or unequal density. The method is based on the combined capillary rises of both liquids in the tube.

\section{SUBJECT TERMS}

Interfacial tension; Capillary tube; Equal density liquids; Immiscible

15. NUMBER OF PAGES

10

16. PRICE CODE

$\mathrm{AO} 3$

\section{SECURITY CLASSIFICATION OF REPORT} Unclassified

18. SECURITY CLASSIFICATION
OF THIS PAGE
Unclassified

Unclassified
19. SECUATYY CLASSIFICATION OF ABSTRACT Unclassified 